\title{
The Effects of Impregnation of Precious Metals on the Catalytic Activity of Titanium Silicate (TS-1) in Epoxidation of Propene Using Hydrogen Peroxide
}

\author{
Sang Baek Shin ${ }^{a, \dagger, *}$, Dae-Won Lee ${ }^{b}$, and David Chadwick ${ }^{a, *}$ \\ ${ }^{a}$ Department of Chemical Engineering, Imperial College London, London SW7 2AZ, United Kingdom \\ ${ }^{b}$ Department of Chemical Engineering, Kangwon National University, 1 Kangwondaehak-gil, \\ Chuncheon-si, Gangwon-do 200-701, Republic of Korea \\ ${ }^{\dagger}$ Current Affiliation: Environmental Catalysts Department, R\&D Centre, Yara International ASA, \\ 3936 Porsgrunn, Norway \\ * Corresponding author 1 (Sang Baek Shin): Tel.: +47 40618565 ; Fax: +47 24158213 ; E-mail: \\ sang.baek.shin@yara.com.
}

* Corresponding author 2 (David Chadwick): Tel.: +44 (0)20 75945579 ; Fax: +44 (0)20 7594 5637 ; E-mail: d.chadwick@imperial.ac.uk.

※ Sang Baek Shin will fulfill all the corresponding duties during the review and publication process. 


\begin{abstract}
Propene oxide is an important chemical intermediate and titanium silicalite (TS-1) has been widely investigated as a promising catalyst for the direct epoxidation of propene with ex-situ or in-situ produced hydrogen peroxide as an oxidant. In order to clarify the effects of the kind of precious metal and treatment process in the catalyst preparation on the propene epoxidation and the hydrogen peroxide decomposition, TS-1 was impregnated with gold and palladium via drying, calcination and reduction and the experiments to check its catalytic performance were conducted in a gas aspirating autoclave reactor in the absence of mass transfer limitations. The presence of precious metals vigorously catalyzed the side reactions and hydrogen peroxide decomposition. Some of the precious metal containing TS-1 catalysts showed high initial rates but there was no catalyst with a propene oxide yield after $5 \mathrm{~h}$ reaction time comparable to TS1 alone because of the enhancement of side reactions by precious metals. The significant decline in the selectivity to propene oxide over the dried precious metal containing TS-1 catalysts was attributed to the leaching of precious metals into the reaction medium. Palladium containing TS-1 showed exceptionally high decomposition of hydrogen peroxide. Reduction and calcination increased the decomposition by forming metallic gold and palladium. Homogeneous dispersion of gold nanoparticles was achieved by a sol immobilization method which led to a decrease of propene oxide selectivity and an increase of hydrogen peroxide decomposition.
\end{abstract}

Keywords: propene oxide; hydrogen peroxide; epoxidation; TS-1; precious metal 


\section{Introduction}

Propene oxide is an important raw material for the production of polyether polyols, propene glycols, and propene glycol ethers [1-3]. In several liquid-phase epoxidation routes to convert propene into propene oxide, much attention has been directed to heterogeneous catalytic oxidation using hydrogen peroxide as a more environmentally benign and profitable chemical process [1-15]. Titanium silicalite (TS-1) catalyst has been extensively investigated for this route because propene oxide can be produced with a high selectivity in methanol under mild conditions $[4,5,10-23]$. The direct epoxidation process based on hydrogen peroxide (oxidant) and TS-1 (catalyst) was commercialized and referred to as "hydrogen peroxide-to-propene oxide" (HPPO) process. The first commercial-scale HPPO plant (production capacity: 100 kton/year) was built by Evonik and SKC in Ulsan, South Korea in 2008 [13]. Since 2009, several HPPO plants of 100 - $400 \mathrm{kton} /$ year capacity have been launched in many places of the world, including Thailand, Belgium, China, etc $[13,24]$. However, from a green chemistry point of view, employing ex-situ produced hydrogen peroxide is less attractive due to the use of toxic chemicals and generation of a large amount of waste in the current process for hydrogen peroxide production (e.g., anthraquinone process) [25]. Moreover, hydrogen peroxide produced via anthraquinone process has remained relatively expensive.

It is anticipated that the direct gas-phase epoxidation of propene using $\mathrm{O}_{2}$ or a mixture of $\mathrm{O}_{2}$ and $\mathrm{H}_{2}$ might take over the next generation after the HPPO process, but currently available catalysts have difficulty in attaining sufficient conversion of propene for commercial application [1, 3, 14, 26]. Therefore, several attempts have been made to utilize hydrogen peroxide produced in-situ from a mixture of $\mathrm{H}_{2}$ and $\mathrm{O}_{2}$ gas for a liquid-phase epoxidation process [5, 14, 25, 27-36]. For this purpose, the TS-1 catalyst modified by the impregnation of precious metals such as palladium, platinum and gold has been used to generate hydrogen peroxide and oxidize propene at the same time.

Hölderich and colleagues investigated the $\mathrm{O}_{2}-\mathrm{H}_{2}$ system for the liquid-phase epoxidation of propene over Pd or Pd/Pt impregnated TS-1 catalyst [5, 27, 28, 32-34]. They emphasized the role of precious metals, because the in-situ generation of hydrogen peroxide on the precious metal site is the ratedetermining step in the epoxidation reaction [5]. They reported that the influence of calcination carried out prior to reduction on the performance of catalyst was insignificant. The propene oxide yield and selectivity were improved by reducing the catalyst under pure $\mathrm{N}_{2}$ and adding a suitable amount of

platinum as a promoter. The propene oxide selectivity could reach as high as $71 \%$ at a propene 
conversion of $21 \%$ over $1 \% \mathrm{Pd}$ and $0.01 \% \mathrm{Pt}$ on TS- 1 , autoreduced by precursor ligands at $150{ }^{\circ} \mathrm{C}$ under pure $\mathrm{N}_{2}$, in a semi-batch reactor containing a water-methanol mixture as solvent [33]. Beckman and coworkers demonstrated that a higher propene conversion and propene oxide selectivity were achieved over a $(0.2 \% \mathrm{Pd}+0.02 \% \mathrm{Pt}) / \mathrm{TS}-1$ catalyst using compressed $\mathrm{CO}_{2}$ as a solvent and a side reaction inhibitor in a high pressure reactor [25].

Recently, plenty of attention has been paid to the characteristics of $\mathrm{Au}$ and bimetallic $\mathrm{Au}-\mathrm{Pd}$, which have been known to be highly active for the direct synthesis of hydrogen peroxide from $\mathrm{H}_{2}$ and $\mathrm{O}_{2}$ [37-47] when supported on TS-1 for the liquid- or gas-phase epoxidation, and the improvement of precious metals distribution on the surface of TS-1. The homogeneous distribution of $\mathrm{Au}$ is an important factor for epoxidation activity of Au/TS-1 catalyst: Delgass and colleagues studied the optimum conditions of deposition-precipitation (DP) to prepare Au/TS-1 catalyst on which $\mathrm{Au}$ is uniformly dispersed in nanoscale $[42,43]$. Mennemann and Claus claimed that the uptake and distribution of Au could be enhanced by adding $0.2-0.5 \mathrm{wt} \%$ of Co when the catalyst was prepared via DP method [44]. Zahn et al. published a few papers about a new preparation route for $\mathrm{Au} / \mathrm{TS}-1$ catalyst based on biomass-reduction, in which an important issue was also the distribution and stabilization of Au nanoparticles [45, 46].

In this study, we tried to clarify and compare the influences of the kind of precious metal and preparation method on the activity of TS-1 in the liquid-phase epoxidation of propene with $e x$-situ hydrogen peroxide. In particular, we tried to reveal the effects of drying and calcination on the epoxidation activity of the precious-metal-loaded TS-1 catalysts. It is generally known that the use of precious metals are disadvantageous in HPPO reactions, where ex-situ $\mathrm{H}_{2} \mathrm{O}_{2}$ was used as an oxidant: Hölderich and colleagues explained some detrimental effects of Pd loading on the HPPO activity of TS-1 catalysts, such as the blocking of Ti sites of TS-1 by the counter anion of metal precursor, or the decomposition of hydrogen peroxide on the Pd site [5]. However, in spite of such recognition, it has not been fully elucidated yet how the activities of Pd, $\mathrm{Au}, \mathrm{Pd}-\mathrm{Au}$-loaded TS-1 catalysts change along with their preparation procedures (i.e., drying-calcination-reduction). It is supposed that it might be difficult to handle this issue in the previous literatures, because propene oxide yield and selectivity were too low when the catalysts were calcined (or reduced) at high temperature [27].

Another important aim of this work is to apply a sol immobilization method to achieve more homogenous dispersion of $\mathrm{Au}$ nanoparticles on TS-1 support. The sol-immobilized Au/TS-1 was compared with conventional impregnated catalysts in terms of metal distribution and epoxidation activity. 
Even in the $\mathrm{H}_{2}-\mathrm{O}_{2}$ reaction systems, where $\mathrm{H}_{2} \mathrm{O}_{2}$ is generated and consumed in-situ, the precious metalloaded TS-1 catalysts were inactive if they were not prepared in a proper way. It was usually due to agglomeration of precious metals on the outer surface of TS-1, which caused a detrimental impact on the hydrogen peroxide production in the $\mathrm{H}_{2}-\mathrm{O}_{2}$ system [33]. Thus, we tried to induce a homogeneous distribution of Au over TS-1 by applying sol-immobilization method.

Lastly, it should be addressed that the activities were measured under ex-situ hydrogen peroxide reaction system, because in the $\mathrm{H}_{2}-\mathrm{O}_{2}$ systems (i.e. in-situ hydrogen peroxide systems), the supply of hydrogen peroxide is limited due to the occurrence of side reactions to produce water. It was considered that by using ex-situ hydrogen peroxide directly as oxidant, we could separate the effects of the formation of hydrogen peroxide and make the effects more recognizable.

\section{Experimental}

\subsection{Catalyst preparation}

TS-1 catalyst was synthesized according to the method descried in the literature [16, 48]. A solution of $1.5 \mathrm{~g}$ of tetraethyl orthotitanate (TEOT, Fluka) was gradually added to $45 \mathrm{~g}$ of tetraethyl orthosilicate (TEOS, Fluka) with magnetic stirring for $30 \mathrm{~min}$. An aliquot of $100 \mathrm{~g}$ of $20 \mathrm{wt} \%$ tetrapropylammonium hydroxide solution (TPAOH, Fluka) was then gradually added to the mixed solution under stirring. After keeping the mixture at $60{ }^{\circ} \mathrm{C}$ for $3 \mathrm{~h}, 56 \mathrm{~g}$ of deionized water was added to the solution. The molar reagent ratios of the final solution were $\mathrm{SiO}_{2} / \mathrm{TiO}_{2}=32.7, \mathrm{TPAOH} / \mathrm{SiO}_{2}=0.46$, and $\mathrm{H}_{2} \mathrm{O} / \mathrm{SiO}_{2}=35$. The resulting solution was transferred to an autoclave in an oven and crystallized at $175{ }^{\circ} \mathrm{C}$ for $48 \mathrm{~h}$ without stirring. After cooling the solution to room temperature, the crystalline product was separated by centrifugation, washed with deionized water, dried at $100{ }^{\circ} \mathrm{C}$ for $2 \mathrm{~h}$, heated at a rate of $5{ }^{\circ} \mathrm{C} / \mathrm{min}$ and then finally calcined at $550{ }^{\circ} \mathrm{C}$ for $5 \mathrm{~h}$ in an air-atmosphere furnace. The resulting catalyst was ground into a fine powder with a pestle and mortar.

The precious metal containing TS- 1 catalysts were prepared by impregnation using $\mathrm{HAuCl}_{4} \cdot 3 \mathrm{H}_{2} \mathrm{O}$ (Sigma-Aldrich) and $\mathrm{PdCl}_{2}$ (Sigma-Aldrich). TS-1 produced in the same batch - therefore, the molar ratio of $\mathrm{Si} / \mathrm{Ti}$ remained the same - was used and precalculated quantity of precious metal solutions was added with an intention to achieve $1 \%$ content of each precious metal in the resulting catalyst. As a result, the precious metal contents are $1 \%$ and $2 \%$ in the monometallic and bimetallic TS-1 catalysts, respectively. 
$8.2 \mathrm{~g}$ of $1 \mathrm{wt} \% \mathrm{HAuCl}_{4} \cdot 3 \mathrm{H}_{2} \mathrm{O}$ aqueous solution was added to $4 \mathrm{~g}$ of TS-1 for $1 \mathrm{wt} \% \mathrm{Au} / \mathrm{TS}-1.6 .8 \mathrm{~g}$ of 1 wt $\% \mathrm{PdCl}_{2}$ aqueous solution was added to $4 \mathrm{~g}$ of TS- 1 for $1 \mathrm{wt} \% \mathrm{Pd} / \mathrm{TS}-1$. For $1 \mathrm{wt} \% \mathrm{Au}-1 \mathrm{wt} \% \mathrm{Pd} / \mathrm{TS}-1$, $8.4 \mathrm{~g}$ of $1 \mathrm{wt} \% \mathrm{HAuCl}_{4} \cdot 3 \mathrm{H}_{2} \mathrm{O}$ aqueous solution and $7 \mathrm{~g}$ of $1 \mathrm{wt} \% \mathrm{PdCl}_{2}$ aqueous solution were simultaneously added to $4 \mathrm{~g}$ of TS-1. After mixing for $30 \mathrm{~min}$, all samples were dried at $90{ }^{\circ} \mathrm{C}$ for $15 \mathrm{~h}$. Some of each dried catalyst was heated at a rate of $5{ }^{\circ} \mathrm{C} / \mathrm{min}$ and calcined in static air at $400{ }^{\circ} \mathrm{C}$ for $3 \mathrm{~h}$. Some of each dried catalyst was reduced with $10 \% \mathrm{H}_{2}$ in $\mathrm{Ar}$ at a flow rate of $100 \mathrm{~mL} / \mathrm{min}$ and a heating rate of $2{ }^{\circ} \mathrm{C} / \mathrm{min}$ from room temperature to $200{ }^{\circ} \mathrm{C}$ at which the catalyst was kept for $3 \mathrm{~h}$. In this paper, these catalysts would be named as dried, calcined or reduced catalyst according to its treatment process of supporting precious metals on TS-1.

The Au/TS-1 catalyst was also synthesized by a sol immobilization method using a stabilizing agent to control the size and dispersion of gold nanoparticles. A gold sol prepared using Tetrakis(hydroxymethyl)phosphonium chloride (THPC, Sigma-Aldrich)/ $\mathrm{NaOH}$ was used as a stabilizing system as described in the literature [49]. For the preparation of $1 \mathrm{wt} \% \mathrm{Au}$ on TS-1 catalyst, $230 \mathrm{~mL}$ of deionized water, $10 \mathrm{~mL}$ of $0.2 \mathrm{M} \mathrm{NaOH}$ solution and $4 \mathrm{~mL}$ of THPC solution ( $1 \mathrm{~mL}$ of $80 \mathrm{wt} \%$ THPC in $100 \mathrm{~mL}$ deionized water) were mixed under stirring. After a few minutes a solution of $0.139 \mathrm{~mL}$ of $\mathrm{HAuCl}_{4}(30 \mathrm{wt} \%$, Sigma-Aldrich) in $5 \mathrm{~mL}$ of deionized water was added. There was an immediate change of colour of the solution into dark brown indicating the formation of the gold sol. Then, $4 \mathrm{~g}$ of TS-1 was suspended in $300 \mathrm{~mL}$ deionized water for 10 min under stirring at $\mathrm{pH} 2$. The gold sol was then dropped onto the TS-1 slurry with stirring for $1 \mathrm{~h}$. The catalyst was filtered, washed chlorine-free and dried. To remove all THPC, the dried catalyst was heated at a rate of $2{ }^{\circ} \mathrm{C} / \mathrm{min}$ and treated with $10 \% \mathrm{H}_{2}$ in $\mathrm{N}_{2}$ at a flow rate of $25 \mathrm{~mL} / \mathrm{min}$ at $350{ }^{\circ} \mathrm{C}$ for $2 \mathrm{~h}$.

\subsection{Characterization}

The crystallographic structure of catalyst was identified on a PANalytical X'Pert PRO X-ray powder diffractometer equipped with a nickel filter and $\mathrm{Cu} K \alpha$ radiation $(\lambda=1.541 \AA)$. Bragg angles between $5^{\circ}$ and $50^{\circ}$ were scanned with a $0.0042^{\circ}$ step size. Elemental analysis was performed by X-ray fluorescence (XRF) using Bruker AXS. Scanning electron microscopy (SEM) images were recorded on a Leo Gemini 1525 instrument to inspect the morphology of catalyst. The dispersion of precious metals was investigated by transmission electron microscopy (TEM) images taken on a JEOL JEM 2010. Brunauer-Emmett- 
Teller (BET) analysis data was obtained by $\mathrm{N}_{2}$ adsorption and desorption in a Micromeritics TriStar 3000 apparatus.

\subsection{Epoxidation of propene}

A $200 \mathrm{~mL}$ thick-walled glass Büchi autoclave system constructed by Strata Technology Ltd. was used for batch experiments. The reaction tests were carried out in a magnetic-drive-stirred autoclave reactor which was immersed in a water bath to control the reaction temperature. In a typical run, a mixture consisting of $0.68 \mathrm{~g}$ of $35 \mathrm{wt} \%$ hydrogen peroxide, $35 \mathrm{~g}$ of methanol and $34.32 \mathrm{~g}$ of deionized water was placed in the autoclave reactor after the water bath was heated to a certain temperature that is the same as or a little higher than a predetermined reaction temperature $\left(40{ }^{\circ} \mathrm{C}\right)$. A small sample was taken to determine the initial concentration of hydrogen peroxide before the introduction of the catalyst. Then, $0.28 \mathrm{~g}$ of catalyst was added, and the reactor was closed. The rotational speed of the gas entrainment stirrer was set at $1000 \mathrm{rpm}$ and maintained throughout experiment. The reactor was heated to reach the predetermined reaction temperature. When the set temperature was reached, the reactor was charged with $10 \%$ propene in $\mathrm{N}_{2}$ at a predetermined total pressure $(7$ bar) to initiate the reaction. The steps from catalyst addition to reaction initiation were completed quickly, i.e. within a few minutes. Therefore, $\mathrm{H}_{2} \mathrm{O}_{2}$ decomposition for such duration would be negligible and it can be assumed that the initial $\mathrm{H}_{2} \mathrm{O}_{2}$ concentration was the same for all experiments. The reaction products were sampled at regular time intervals through a dip tube.

The concentration of hydrogen peroxide was determined by iodometric titration. Liquid samples were analyzed on a gas chromatograph (Shimadzu GC-2014) equipped with a flame ionization detector and a capillary column $(30 \mathrm{~m} \times 0.32 \mathrm{~mm})$ with nitroterephthalic acid-modified polyethylene glycol $(0.25 \mu \mathrm{m})$ as the stationary phase.

The initial rates of the chemical reaction were calculated from tangential slopes at $\mathrm{t}=0$ using exponential curve fitting.

The reason for using ex-situ hydrogen peroxide in this study is to distinguish the influence of precious metals and preparation methods on the propene oxide production and hydrogen peroxide decomposition from the formation of hydrogen peroxide, because hydrogen peroxide produced in-situ is immediately consumed for the reaction with propene and the decomposition into water and oxygen and therefore its concentration measured is very low. Also, the propene oxide yield and selectivity remains somewhat low 
in the $\mathrm{H}_{2}-\mathrm{O}_{2}$ system, which makes the impact of experimental factors less recognizable [27, 28]. Accordingly, the experimental conditions of this study are rather different from those of Hölderich's research group where propene condensate was used under high pressure of $\mathrm{H}_{2}, \mathrm{O}_{2}$ and $\mathrm{N}_{2}$.

\section{Results and discussion}

\subsection{Catalyst characterization}

The analysis results of TS-1 catalyst showed good agreement with the data indicated in the original patent [48]. In the SEM image of TS-1 shown in Fig. 1, it is observed that well-defined, uniform cubic crystallites with rounding edges are distributed homogeneously. It is known that TS-1 crystallizes in the form of slightly rounded cubes when crystallization occurs in a static autoclave and that this shape is more active for the epoxidation of propene than other shapes such as sphere and twinned coffin $[50,51]$. The size of the particles was in the range of $200-300 \mathrm{~nm}$. The TS-1 prepared in this study therefore had a suitable shape and particle size to exhibit sufficient activity for the epoxidation of propene largely free of intra-particle mass transfer resistance [52].

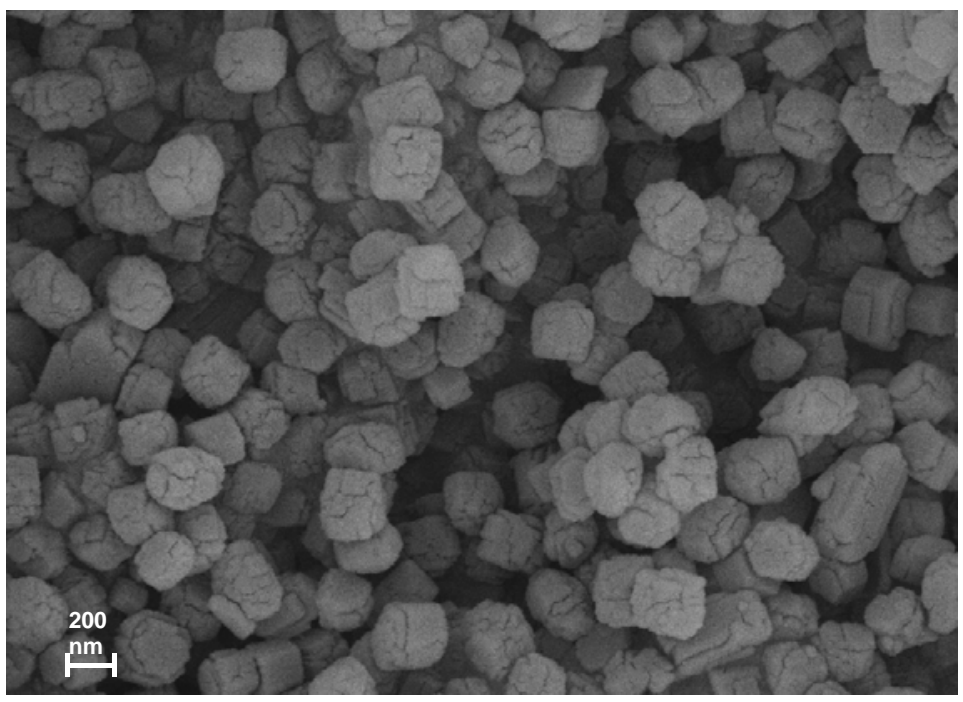

Fig. 1. SEM micrograph of TS-1 catalyst.

In the FT-IR spectrum of TS-1 ([52], not shown here), there was a characteristic absorption band at $971.4 \mathrm{~cm}^{-1}$ which is not present in the spectrum of either pure silicalites or titanium oxides. The FT-IR spectra of precious metal containing TS-1 catalysts confirmed that there was no change of framework of 
TS-1 during precious metal impregnation and treatment process. In the BET analysis, there was also no distinction between TS-1 and precious metal containing TS-1. All catalysts had a surface area of approximately $415 \mathrm{~m}^{2} / \mathrm{g}$.

The molar ratio of $\mathrm{Si} / \mathrm{Ti}$ in the lattice framework of TS-1 determined by a semi-quantitative XRF analysis was found to be 50 . This value is higher than the molar reagent ratio of 32.7 used in the TS- 1 synthesis. It has been reported that the maximum mole fraction of titanium incorporated in the TS-1 framework is 0.025 which corresponds to $\mathrm{Si} / \mathrm{Ti}$ molar ratio of 39 [53-55]. The contents of precious metal determined by the XRF measurements were found to be $0.7 \mathrm{wt} \%-0.9 \mathrm{wt} \%$ of target loading. However, the loading of gold on TS-1 by sol immobilization was lower and found to be $0.54 \mathrm{wt} \%$.

Fig. 2 shows the TEM images of precious metal containing TS- 1 catalysts prepared by different treatment processes. Gold nanoparticles of roughly $2-8 \mathrm{~nm}$ in size are dispersed on the exterior of the dried $\mathrm{Au} / \mathrm{TS}-1$. However, most of the gold nanoparticles are agglomerated into clusters in a size of $50-$ $100 \mathrm{~nm}$ by calcination carried out at the high temperature. The size of palladium nanoparticles is approximately $1-4 \mathrm{~nm}$ which is smaller than gold nanoparticles. It is observed to form clusters even in the dried Pd/TS-1 because of high mobility of palladium nanoparticles. The clumping of palladium nanoparticles was also promoted by calcination, which led to circular clusters. Gold and palladium nanoparticles coexist in the Au-Pd/TS-1 but it is impossible to distinguish each other and detect the alloy of gold and palladium from the images. In the calcined precious metal containing catalysts, it is difficult to observe gold or palladium nanoparticles present separated from their clusters. However, the distribution of precious metals seems to be slightly improved by reduction.
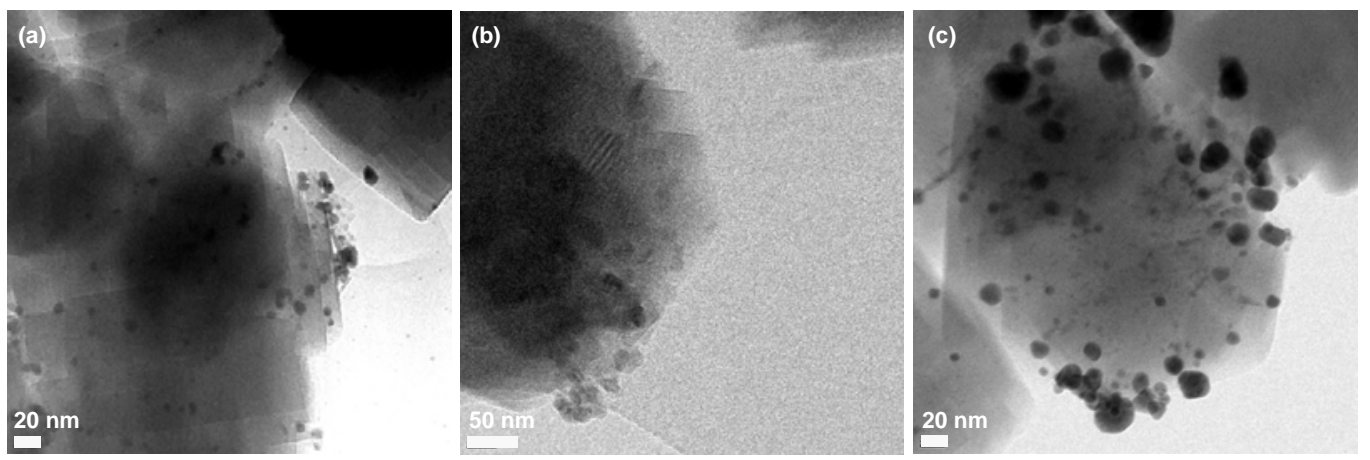

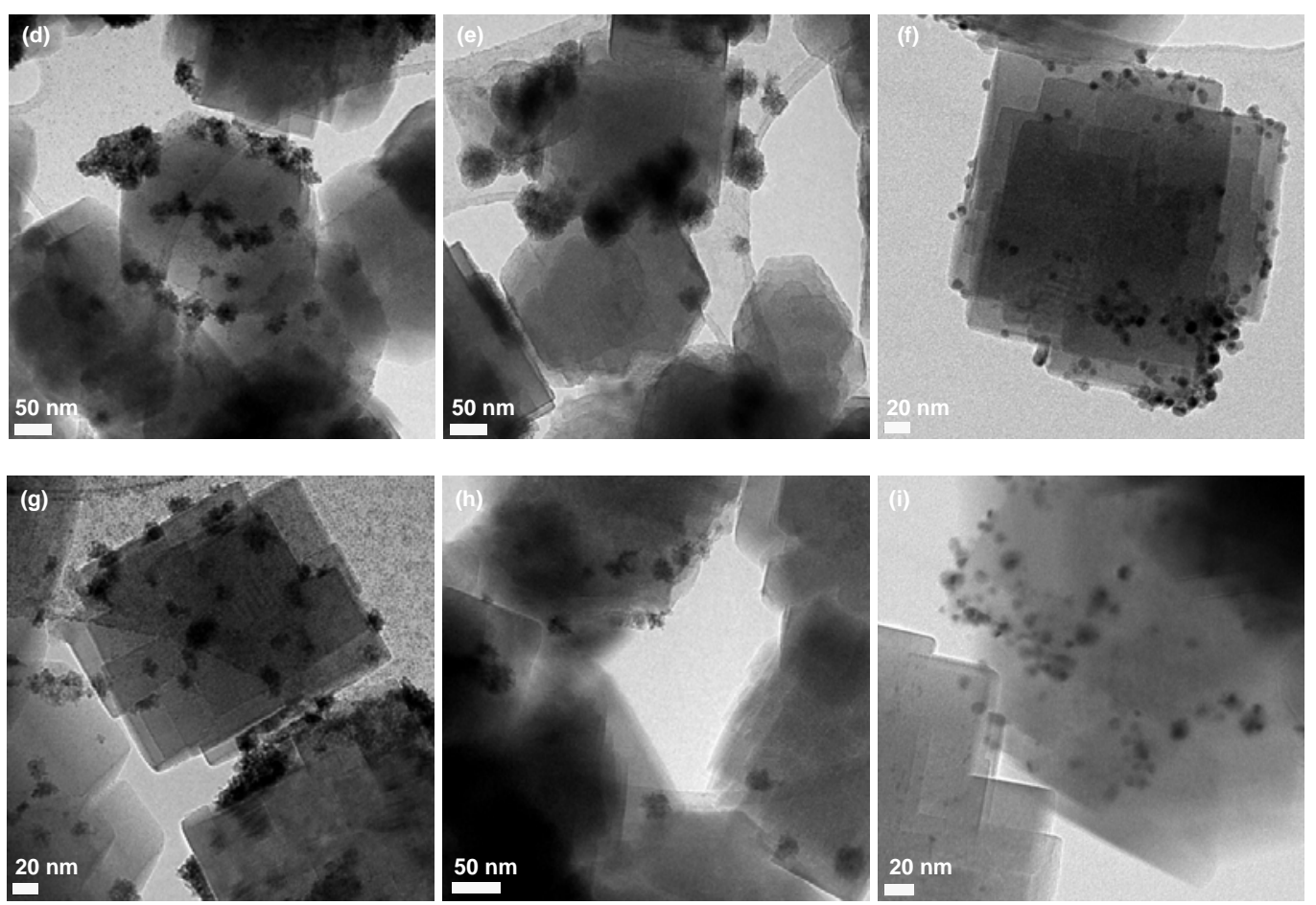

Fig. 2. TEM micrographs: (a) Au/TS-1 dried, (b) Au/TS-1 calcined, (c) Au/TS-1 reduced, (d) Pd/TS-1 dried, (e) Pd/TS-1 calcined, (f) Pd/TS-1 reduced, (g) Au-Pd/TS-1 dried, (h) Au-Pd/TS-1 calcined and (i) $\mathrm{Au}-\mathrm{Pd} / \mathrm{TS}-1$ reduced.

Inhomogeneous dispersion and large clusters of precious metal nanoparticles found in the TEM images can lead to a decline in catalyst activity due to a loss of effective surface area. The distribution of precious metals on TS-1 by impregnation method was improved by reduction but was still unsatisfactory. Therefore, a sol immobilization method was applied to the Au/TS-1. As shown in Fig. 3, an outstanding result of gold dispersion was achieved by this method. In addition, similarly as Grunwaldt et al. [49] suggested, keeping the $\mathrm{pH}$ of catalyst solution significantly below the isoelectric point of TS-1 was essential to effectively immobilize gold nanoparticles. A desired performance of sol immobilization method was achieved at $\mathrm{pH}=2$. 


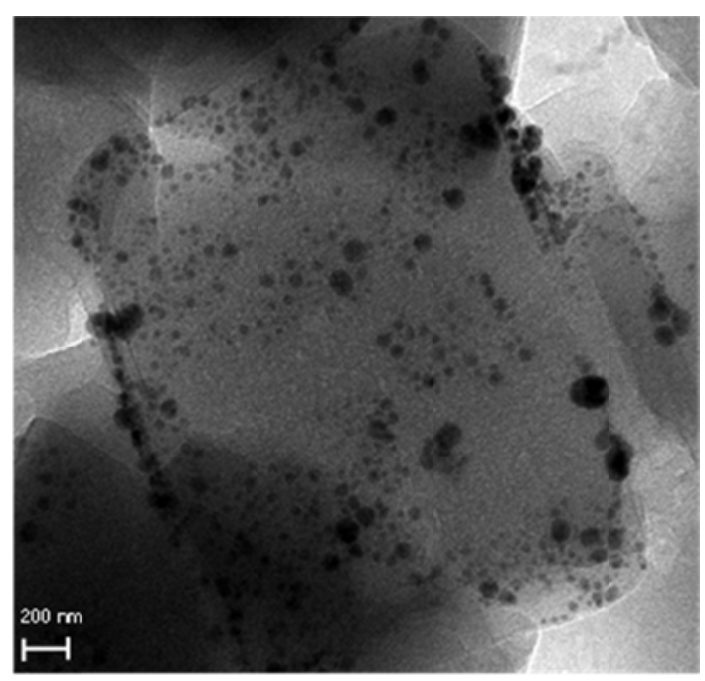

Fig. 3. TEM micrograph of Au/TS-1 prepared by sol immobilization.

The two single peaks at $24.4^{\circ}$ and $29.3^{\circ}$ in the XRD pattern of TS- 1 shown in Fig. 4(a) confirm a conversion from a monoclinic symmetry of silicalite to an orthorhombic symmetry of titanium silicalite. Consistent with the results of the FT-IR and BET analysis results, there was no difference of fingerprint peaks in the XRD spectrum between TS-1 and precious metal impregnated TS-1, which confirmed again that the MFI structure of TS-1 was not modified by impregnation and treatment process. In Fig. 4(b), the peaks of $\mathrm{Au}^{0}(111)$ and $\mathrm{Au}^{0}(200)$ are clearly observed in the calcined or reduced gold containing TS-1. The existence of $\mathrm{Au}^{0}$ peaks in the calcined catalysts demonstrates that the catalyst was autoreduced by thermal decomposition at high temperature. However, there is no peak of $\mathrm{Au}^{0}$ in the dried $\mathrm{Au} / \mathrm{TS}-1$, which means that gold is still present as $\mathrm{Au}(\mathrm{III})$. As expected from the TEM image of Au/TS-1 prepared by sol immobilization method, a weak and broad peak of $\mathrm{Au}^{0}(111)$ was observed due to even distribution of gold nanoparticles. 
(a)
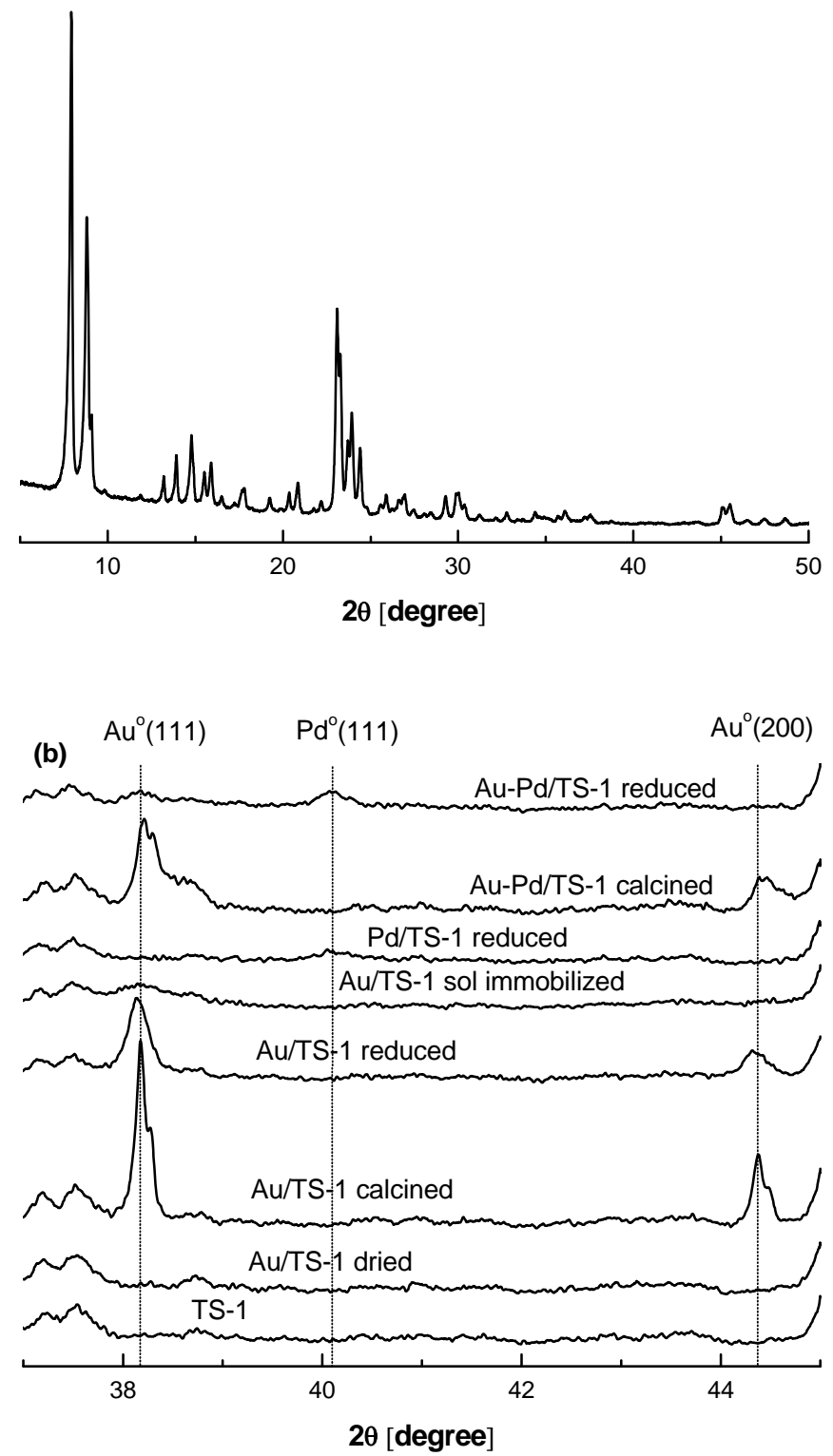

Fig. 4. X-ray diffraction patterns: (a) TS-1 and (b) Au/TS-1, Pd/TS-1 and Au-Pd/TS-1 catalysts.

The reflection belonging to $\mathrm{Pd}^{0}(111)$ can be identified in the reduced palladium containing TS-1 but very weak and broad, indicating the presence of small particle size of palladium. The peaks of gold in the calcined Au-Pd/TS-1 are relatively small in intensity and shifted to a bit higher angles when compared with the calcined $\mathrm{Au} / \mathrm{TS}-1$, which proves the formation of alloy between gold and palladium. Moreover, no peak of $\mathrm{Pd}^{0}$ in calcined $\mathrm{Au}-\mathrm{Pd} / \mathrm{TS}-1$ also illustrated that most of the palladium exists in the Au-Pd alloy structure. 
3.2. Performance of unsupported TS-1 at normal operating conditions

Hydrogen peroxide decomposes into water and oxygen gas $\left(2 \mathrm{H}_{2} \mathrm{O}_{2} \rightarrow 2 \mathrm{H}_{2} \mathrm{O}+\mathrm{O}_{2}\right)$ and the decomposition is known to be catalysed by various metals and compounds $[56,57]$. Therefore, it is necessary to check the possibility of hydrogen peroxide decomposition by reactor metal prior to the propene epoxidation experiments in the Büchi autoclave system. It was examined under normal operating conditions $\left(40{ }^{\circ} \mathrm{C}, 7\right.$ bar $\mathrm{N}_{2}, 0.35 \mathrm{wt} \% \mathrm{H}_{2} \mathrm{O}_{2}, 50 \mathrm{wt} \% \mathrm{CH}_{3} \mathrm{OH}, 1000 \mathrm{rpm}$ stirring) employed in this study and found to be negligible as only $0.3 \%$ of hydrogen peroxide was decomposed after $5 \mathrm{~h}$.

The propene epoxidation was tested at milder conditions than previous studies $[4,16,21,58]$, i.e. lower concentrations of reactants and pressures. $50 \mathrm{wt} \%$ methanol in water was used as solvent because it was known that the selectivity to propene oxide drastically decreased when the water content is more than $50 \%[16,21,58]$. In order to remove mass-transfer resistances, a self-aspirating stirrer was used to intensify the contact between gas and liquid by recycling gas inside solvent mixture and its agitation speed was kept at $1000 \mathrm{rpm}$ throughout experiment. The absence of mass-transfer limitations was also confirmed by calculating the Mears criterion and the effectiveness factor [52].

Fig. 5 shows the performance of TS-1 at normal operating conditions in the autoclave reactor. TS-1 catalyst prepared in this study showed a high catalytic activity comparable to the results reported in the previous literature $[16,59]$. After $5 \mathrm{~h}, 92 \%$ of hydrogen peroxide was consumed. The selectivity to propene oxide gradually decreased with time to $93 \%$ after $5 \mathrm{~h}$. This is because all of the byproducts are generated from propene oxide by the cleavage of epoxide ring attacked by nucleophiles [17]. The main byproducts were 1-methoxy-2-propanol (1M2P) and 2-methoxy-1-propanol (2M1P) and 1, 2-propanediol (12PD). In addition, a small amount of 3-methoxy-1-propanol (3M1P) was also detected, but no 1, 3propanediol (13PD) was observed. For instance, the selectivities to 1M2P, 2M1P, 12PD, 3M1P and 13PD after $5 \mathrm{~h}$ were $2.9,2,9,1.1,0.2$ and $0 \%$, respectively. 


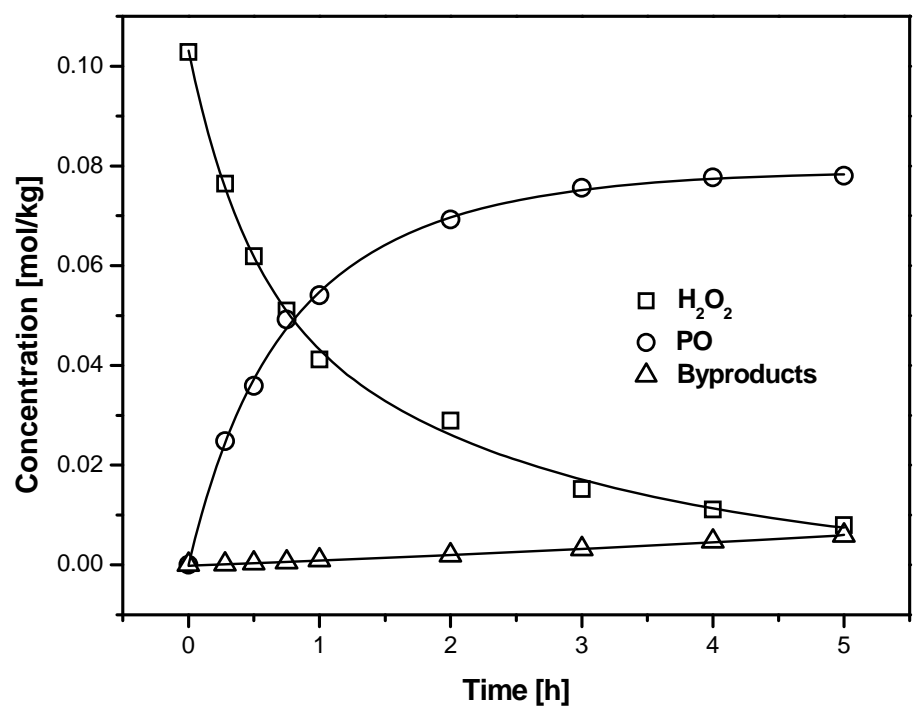

Fig. 5. Propene epoxidation over TS- 1 catalyst in an autoclave reactor at normal operating conditions. Conditions: $40{ }^{\circ} \mathrm{C}, 7$ bar $\left(10 \% \mathrm{C}_{3} \mathrm{H}_{6} / \mathrm{N}_{2}\right), 0.35 \mathrm{wt} \% \mathrm{H}_{2} \mathrm{O}_{2}, 50 \mathrm{wt} \% \mathrm{CH}_{3} \mathrm{OH}, 0.28 \mathrm{~g}$ of TS- $1,1000 \mathrm{rpm}$ stirring.

\subsection{Decomposition of hydrogen peroxide over precious metal-loaded TS-1 catalysts}

Precious metals such as gold and palladium are active for the synthesis of hydrogen peroxide but also catalyze the decomposition of hydrogen peroxide [37-39, 60]. Therefore, prior to commencing the investigation into the influences of precious metal and treatment process on the propene epoxidation, hydrogen peroxide decomposition by each catalyst was checked. In Fig. 6, it was found that the decomposition of hydrogen peroxide is more vigorous on palladium than on gold. The effect of treatment process on the decomposition was varied according to the kind of precious metal. The degree of hydrogen peroxide decomposition was maintained in the dried Au/TS-1 when compared with TS- 1 alone, but increased by calcination and reduction. In the palladium containing TS-1, the decomposition of hydrogen peroxide was serious even in the dried Pd/TS-1 and drastically increased only by reduction. More severe decomposition of hydrogen peroxide observed in the calcined or reduced catalysts can be explained by the presence of metallic phase of precious metals. 


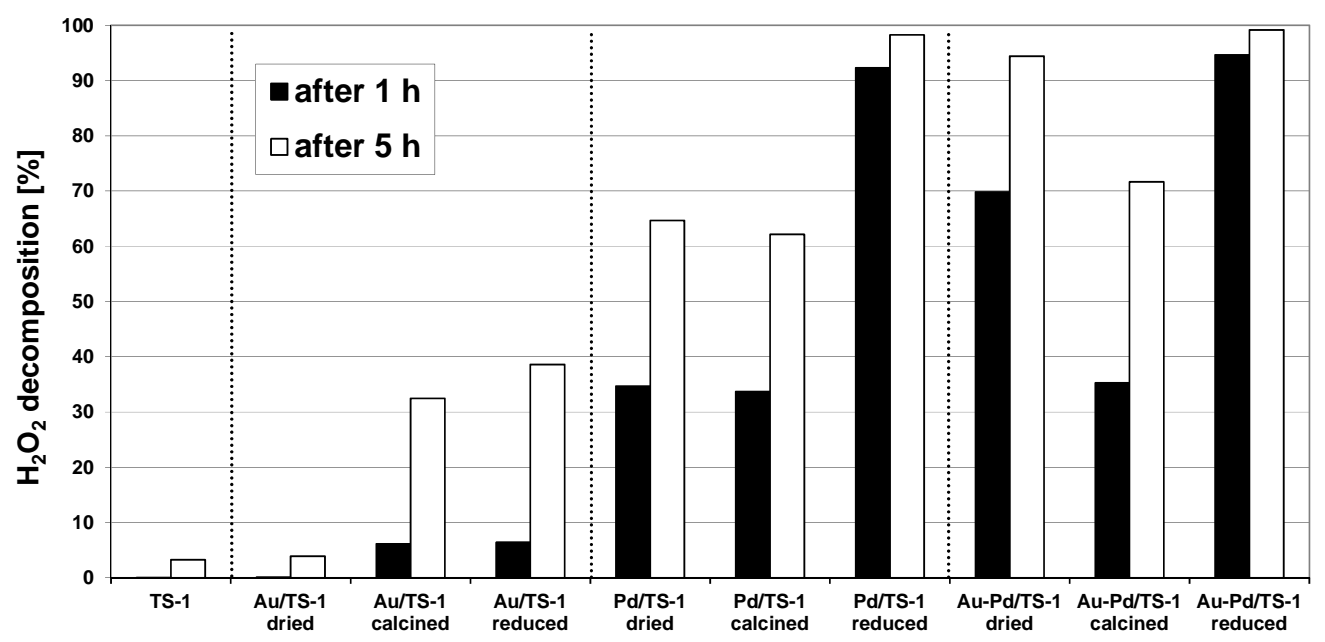

Fig. 6. Decomposition of hydrogen peroxide over various precious metals containing TS-1 catalysts. Conditions: $40^{\circ} \mathrm{C}, 7$ bar $\mathrm{N}_{2}, 0.35 \mathrm{wt} \% \mathrm{H}_{2} \mathrm{O}_{2}, 50 \mathrm{wt} \% \mathrm{CH}_{3} \mathrm{OH}, 0.28 \mathrm{~g}$ of TS-1, $1000 \mathrm{rpm}$ stirring.

Basically, higher decomposition of hydrogen peroxide was observed in the Au-Pd/TS-1 as a total amount of precious metals increased, but interestingly the decomposition of hydrogen peroxide was lower in the calcined Au-Pd/TS-1 when compared with the dried and reduced Au-Pd/TS-1. A possible explanation for this finding is that the presence of alloy of gold and palladium which was detected in the $\mathrm{XRD}$ analysis can reduce the decomposition of hydrogen peroxide.

\subsection{Epoxidation of propene}

\subsubsection{Monometallic catalyst}

The propene epoxidation is negatively affected by the impregnation of precious metals $[5,28,61]$. In Fig. 7(a), after $5 \mathrm{~h}$, the concentration of propene oxide decreases as TS-1 > calcined Au/TS-1 > reduced Au/TS-1 > dried Au/TS-1. Despite the increase of hydrogen peroxide decomposition (Fig. 6), the concentration of propene oxide was higher over the calcined Au/TS-1 or the reduced Au/TS-1 than over the dried Au/TS-1. As can be seen in Fig. 7(b), the side reactions were promoted by the presence of gold and the order of the selectivity to propene oxide was the same as above. Therefore, it can be said that the production rate of propene oxide over $\mathrm{Au} / \mathrm{TS}-1$ catalyst was affected dominantly not by the hydrogen peroxide decomposition but by the enhancement of side reactions. In particular, the selectivity to propene oxide was extremely low in the dried Au/TS-1 catalyst but improved by calcination or reduction. The cause of this finding will be explained by the leaching of gold particles into the reaction medium in 
section 3.5. As TS-1, the main byproducts were 1M2P, 2M1P and 12PD. The byproducts of dried Au/TS1 to were 1M2P, 2M1P, 12PD, 3M1P and 13PD, whose selectivities after $5 \mathrm{~h}$ were 16.6, 23.9, 24.5, 0.4 and $0 \%$, respectively. In case of calcined $\mathrm{Au} / \mathrm{TS}-1$, the selectivities after $5 \mathrm{~h}$ were $5.5,6.4,4.7,0.2$ and $0 \%$, respectively.
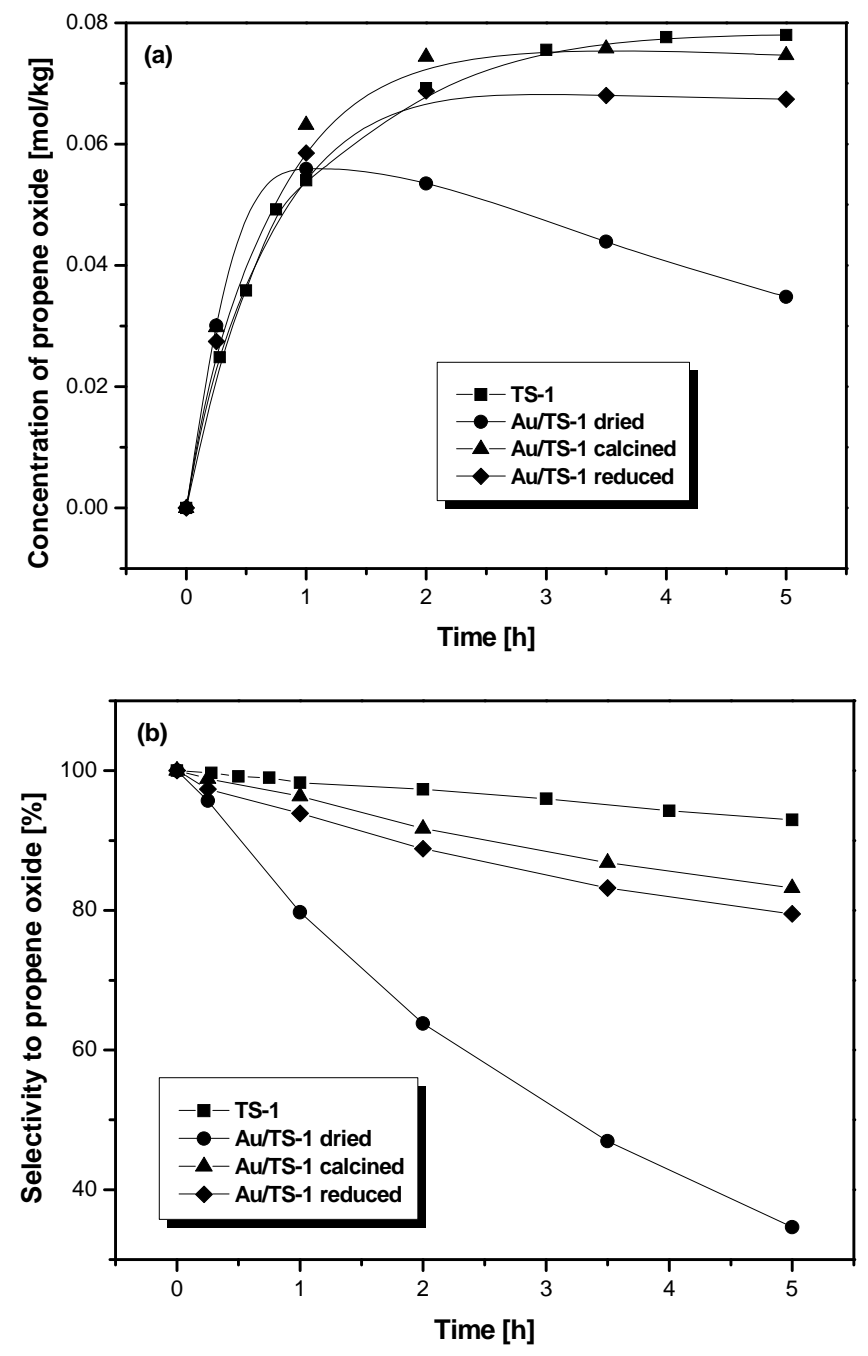

Fig. 7. Propene epoxidation over TS-1 and Au/TS-1 catalysts at normal operating conditions: (a) propene oxide production and (b) selectivity to propene oxide.

When it comes to the initial rates determined by the concentration of propene oxide produced, all the gold containing TS-1 catalysts showed a bit higher initial rates than that of TS-1 alone (Fig. 7(a)).

Fig. 8 shows the results of propene epoxidation over the Pd/TS-1 catalysts. Contrary to the Au/TS-1 catalysts, after $5 \mathrm{~h}$, the concentration of propene oxide was higher over the dried Pd/TS-1 than over the calcined $\mathrm{Pd} / \mathrm{TS}-1$ or the reduced Pd/TS-1. However, the impacts of the treatment processes on the selectivity to propene oxide were similar as shown in Fig. 8(b). Therefore, it can be said that the 
production rate of propene oxide over the $\mathrm{Pd} / \mathrm{TS}-1$ catalyst was affected dominantly by the hydrogen peroxide decomposition (Fig. 6). After 5 h, the selectivity to byproducts in the Pd/TS-1 catalysts was five times higher than that of TS-1 alone. The selectivities of reduced Pd/TS-1 to 1M2P, 2M1P, 12PD, 3M1P and 13PD after $5 \mathrm{~h}$ were 9.7, 13.7, 9.7, 0.4 and $0 \%$, respectively, and dried and calcined Pd/TS-1 showed a similar composition of selectivities.
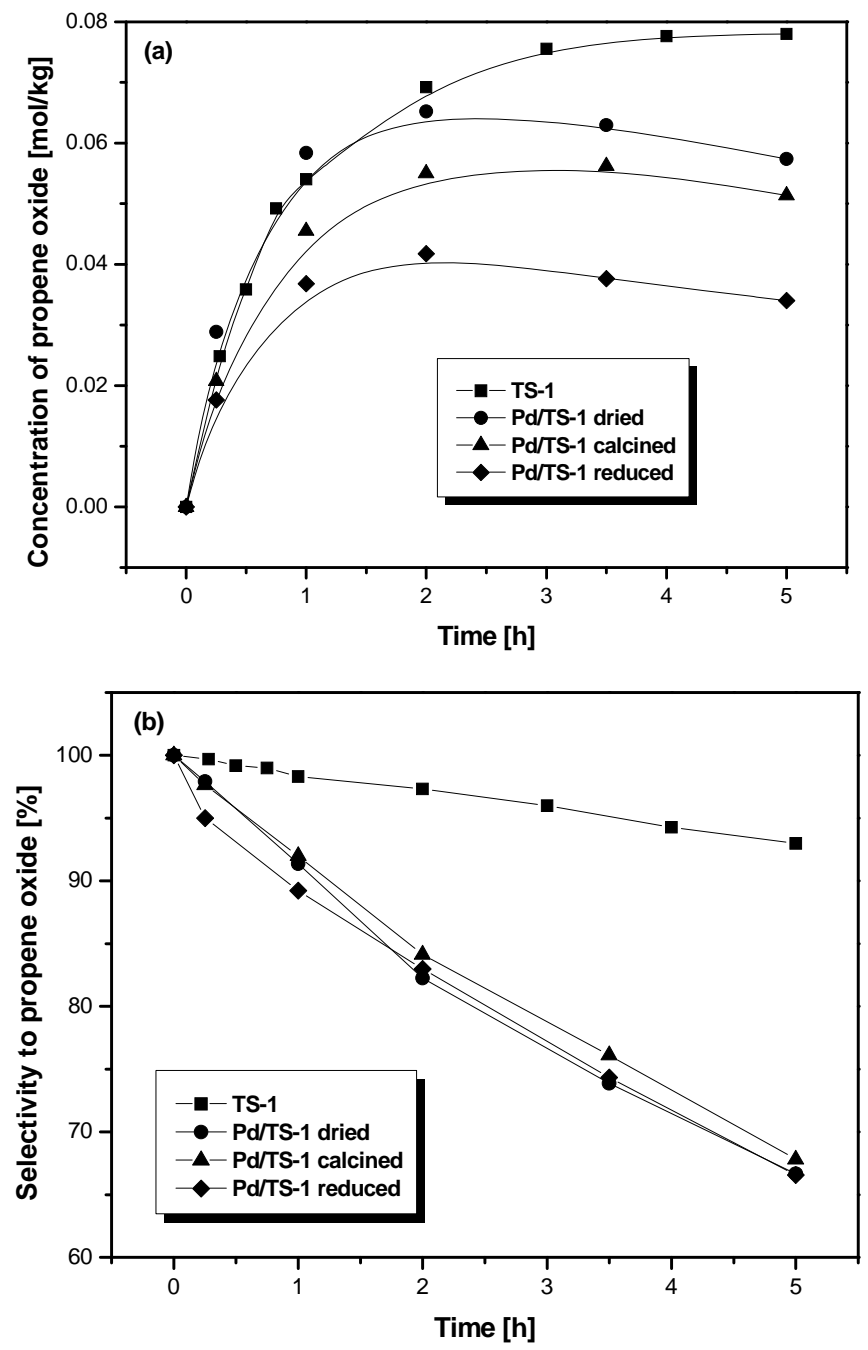

Fig. 8. Propene epoxidation over TS-1 and Pd/TS-1 catalysts at normal operating conditions: (a) propene oxide production and (b) selectivity to propene oxide.

As can be seen in Fig. 8(a), the dried Pd/TS-1 had a higher initial rate than TS-1 alone but calcination and reduction decreased the initial rates which were below that of TS- 1 alone. Therefore, the calcination or the reduction of $\mathrm{Pd} / \mathrm{TS}-1$ catalyst had no additional positive effect on the initial rate.

\subsubsection{Bimetallic catalyst}


Fig. 9(a) shows the concentration of propene oxide produced over the Au-Pd/TS-1 catalysts. After $5 \mathrm{~h}$, the concentration of propene oxide was higher over the calcined Au-Pd/TS-1 than over the dried AuPd/TS-1 or the reduced Au-Pd/TS-1 because of the significant side reactions over the dried Au-Pd/TS-1 and the vigorous hydrogen peroxide decomposition over the reduced Au-Pd/TS-1. In Fig. 9(b), the selectivity to propene oxide over the dried $\mathrm{Au}-\mathrm{Pd} / \mathrm{TS}-1$ was as low as that over the dried $\mathrm{Au} / \mathrm{TS}-1$ because gold and palladium nanoparticles are physically mixed in this catalyst and the leached gold had a big impact on the selectivity. The selectivity to propene oxide was improved by calcination and reduction due to the immobilization of precious metals. The selectivities of dried Au-Pd/TS-1 to 1M2P, 2M1P, 12PD, $3 \mathrm{M} 1 \mathrm{P}$ and 13PD after $5 \mathrm{~h}$ were 15.9, 22.5, 27.5, 0.7 and $0 \%$, respectively, which were similar to those of dried $\mathrm{Au} / \mathrm{TS}-1$. However, the propene oxide production over the reduced $\mathrm{Au}-\mathrm{Pd} / \mathrm{TS}-1$ was greatly affected by the high decomposition of hydrogen peroxide (Fig. 6).

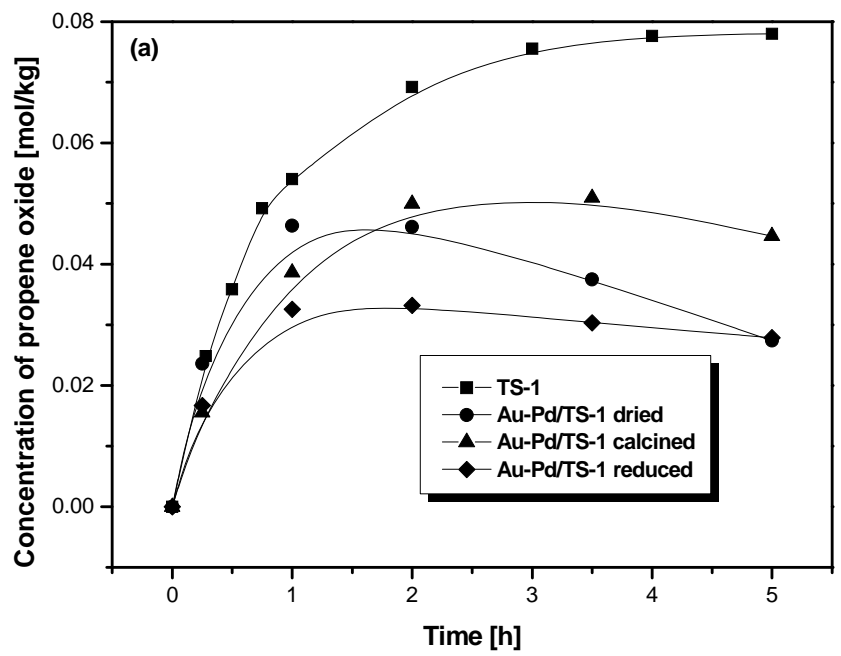




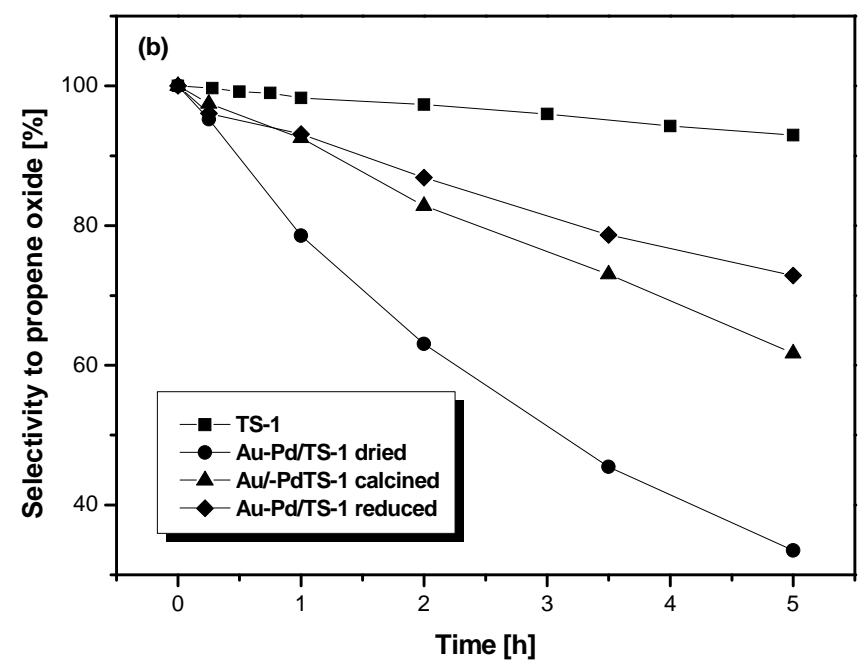

Fig. 9. Propene epoxidation over TS-1 and Au-Pd/TS-1 catalysts at normal operating conditions: (a) propene oxide production and (b) selectivity to propene oxide.

The initial rates of all the Au-Pd/TS-1 catalysts were lower than that of precious metal free TS- 1 . The overall performances were also maintained poor because gold and palladium simultaneously promoted the decomposition of hydrogen peroxide and the production of byproducts.

Fig. 10 shows the yields of propene oxide over various catalysts. After $5 \mathrm{~h}$, there was no catalyst with a higher yield than TS-1 alone because the precious metals enhanced the formation of byproducts. After 1 h, some of the catalysts had higher propene oxide yields but their yields deteriorated over the whole reaction time due to the acceleration of side reactions. The propene oxide yield data must be interpreted with caution because the yield is defined as the multiplication of hydrogen peroxide conversion and propene oxide selectivity and not all the hydrogen peroxide converted is employed for propene oxide production; it is just decomposed into water and oxygen. For example, the high propene oxide yields of the reduced Pd/TS-1 and Au-Pd/TS-1 after $1 \mathrm{~h}$ observed in Fig. 10 are ascribed to their vigorous hydrogen peroxide decomposition, i.e. high hydrogen peroxide conversions, as shown in Fig. 6. 


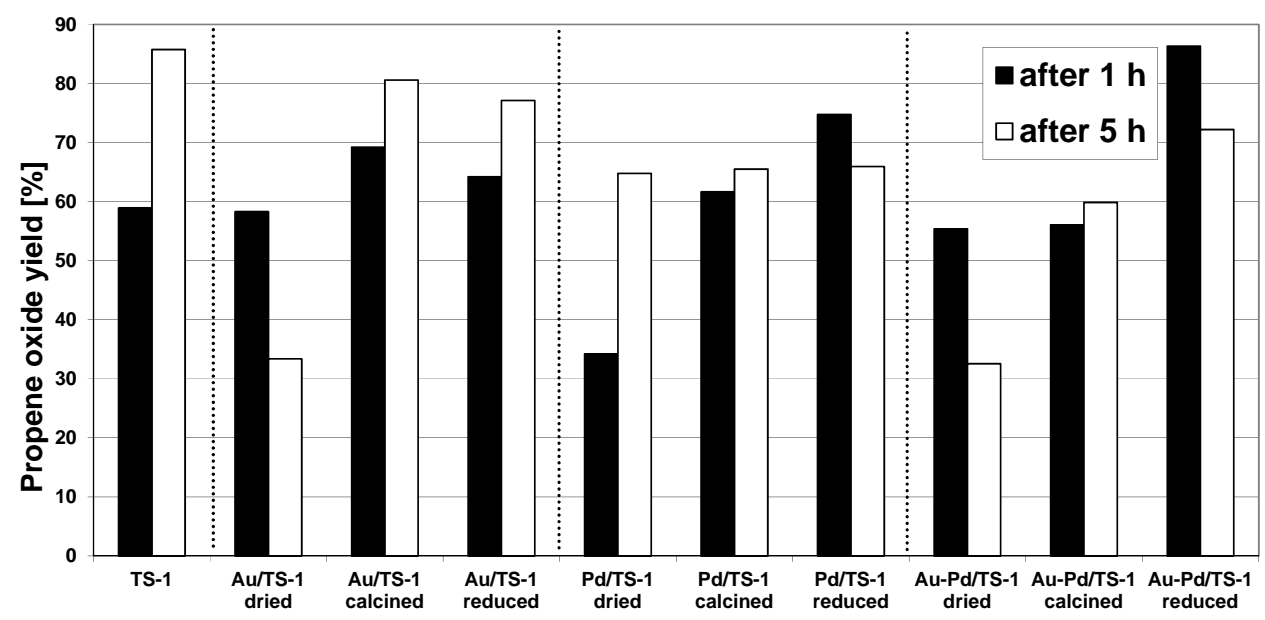

Fig. 10. Propene oxide yield over various precious metals containing TS-1 catalysts at normal operating conditions.

3.5. Decomposition of hydrogen peroxide and conversion of propene oxide over precious metal precursor solutions

The noticeable decrease in the selectivity to propene oxide over the dried catalysts, in particular the dried $\mathrm{Au} / \mathrm{TS}-1$, might be explained by the leaching of precious metals from TS-1 into the reaction medium because the precious metals are thought to be immobilized on the surface of TS-1 particles during the process of calcination or reduction. Therefore, propene epoxidation, hydrogen peroxide decomposition and conversion of propene oxide over precious metal precursor solutions were tested to investigate the effects of the leaching of precious metals. Precious metal solutions containing the amount of gold or palladium which was expected to be incorporated in $0.28 \mathrm{~g}$ of Au or Pd/TS-1 catalysts were used in these tests.

In the propene epoxidation, the $\mathrm{HAuCl}_{4} \cdot 3 \mathrm{H}_{2} \mathrm{O}$ and $\mathrm{PdCl}_{2}$ solution showed a very low activity, which was approximately $1 \%$ of the activity of precious metal free TS- 1 . Therefore, the increased initial rates observed in some of the precious metal containing catalysts suggest that a cooperative function between precious metals and TS-1 exists for the propene epoxidation.

As shown in Fig. 11(a), the degree of hydrogen peroxide decomposition by gold and palladium precursor solutions was quite different. There was almost no decomposition of hydrogen peroxide over the $\mathrm{HAuCl}_{4} \cdot 3 \mathrm{H}_{2} \mathrm{O}$ solution. However, after $5 \mathrm{~h}, 50 \%$ of hydrogen peroxide was decomposed over the $\mathrm{PdCl}_{2}$ solution. This explains the high hydrogen peroxide decomposition in the dried $\mathrm{Pd} / \mathrm{TS}-1$ and the dried Au-Pd/TS-1 catalysts shown in Fig. 6. 

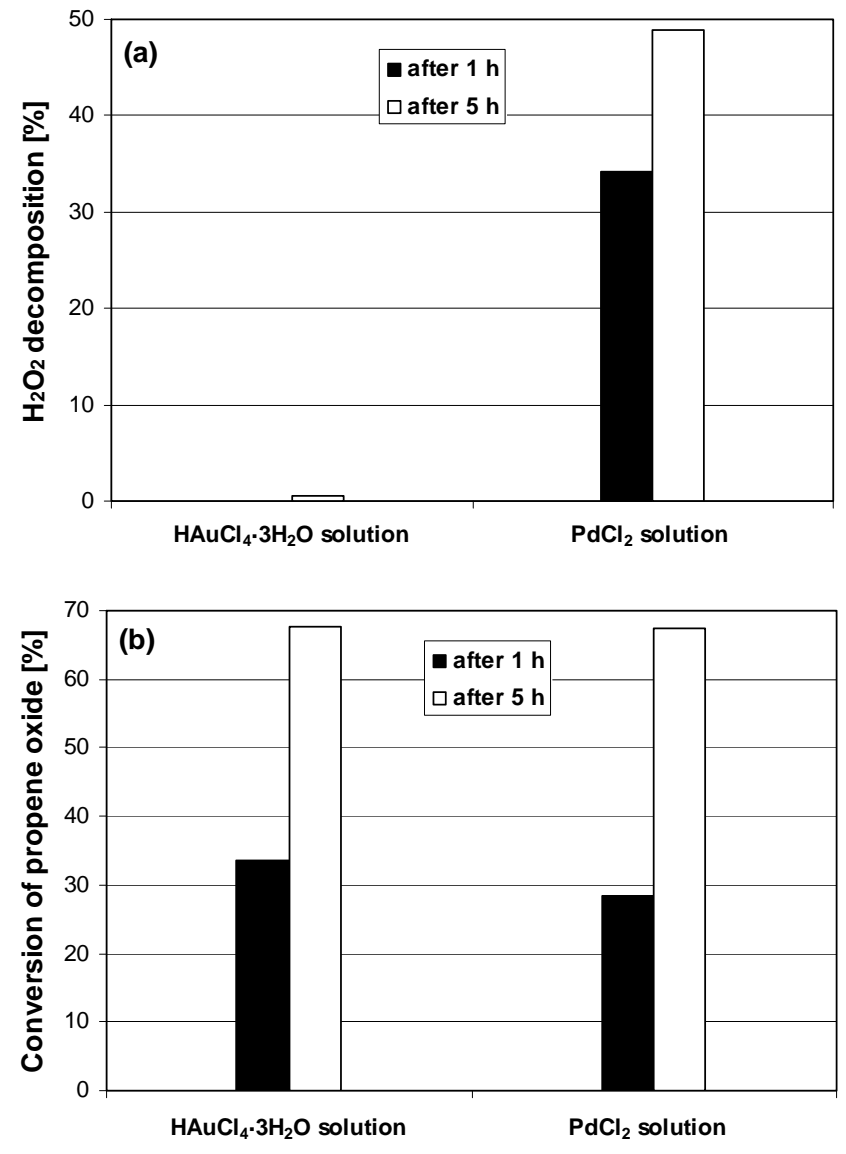

Fig. 11. (a) Decomposition of hydrogen peroxide over $\mathrm{Au}$ and $\mathrm{Pd}$ solution. Conditions: $40{ }^{\circ} \mathrm{C}, 7$ bar $\mathrm{N}_{2}$, $0.35 \mathrm{wt} \% \mathrm{H}_{2} \mathrm{O}_{2}, 50 \mathrm{wt} \% \mathrm{CH}_{3} \mathrm{OH}, 0.57 \mathrm{~g}$ of $1 \mathrm{wt} \% \mathrm{HAuCl}_{4} \cdot 3 \mathrm{H}_{2} \mathrm{O}$ solution, $0.48 \mathrm{~g}$ of $1 \mathrm{wt} \% \mathrm{PdCl}_{2}$ solution, $1000 \mathrm{rpm}$ stirring. (b) Conversion of propene oxide over $\mathrm{Au}$ and Pd solution. Conditions: $40{ }^{\circ} \mathrm{C}, 7$ bar $\mathrm{N}_{2}$, $0.35 \mathrm{wt} \% \mathrm{H}_{2} \mathrm{O}_{2}, 50 \mathrm{wt} \% \mathrm{CH}_{3} \mathrm{OH}, 0.5 \mathrm{wt} \% \mathrm{C}_{3} \mathrm{H}_{6} \mathrm{O}, 0.57 \mathrm{~g}$ of $1 \mathrm{wt} \% \mathrm{HAuCl}_{4} \cdot 3 \mathrm{H}_{2} \mathrm{O}$ solution, $0.48 \mathrm{~g}$ of $1 \mathrm{wt} \%$ $\mathrm{PdCl}_{2}$ solution, $1000 \mathrm{rpm}$ stirring.

Fig. 11(b) shows the conversion of propene oxide to byproducts over the precious metal solutions. To investigate the effect of leached precious metals on side reactions, a suitable amount of liquid propene oxide was included in the initial solvent solutions because all byproducts are produced from propene oxide. Fig. 11(b) indicates that gold and palladium precursor solutions make the similar contribution to the side reactions. Therefore, it demonstrates that the high selectivity to byproducts in the dried $\mathrm{Au} / \mathrm{TS}-1$ shown Fig. 7(b) was caused by the leaching of gold. The reason why the selectivity to byproducts in the dried Pd/TS-1 shown in Fig. 8(b) is not as high as the dried Au/TS-1 seems due to that the leaching of palladium is not vigorous as much as gold and a large portion of leached palladium is used for the decomposition of hydrogen peroxide. The gold and palladium solutions showed a similar level of selectivities to 1M2P, 2M1P, 12PD, 3M1P and 13PD. After $5 \mathrm{~h}$, they were 19.1, 26.1, 53.2, 1.6 and $0 \%$ 
over the gold containing solution and $19.1,26.4,53.8,0.7$ and $0 \%$ over the palladium containing solution, respectively.

\subsection{Epoxidation of propene over Au/TS-1 prepared by sol immobilization}

The Au/TS-1 prepared by the sol immobilization method was tested under the same conditions and compared with the reduced $\mathrm{Au} / \mathrm{TS}-1$ prepared by impregnation. There is a more distinctive trend of decreasing propene oxide concentration in the Au/TS-1 (sol immobilization) due to the acceleration of side reactions with time. In Fig. 12(a), the initial rate of Au/TS-1 (sol immobilization) is higher than the reduced $\mathrm{Au} / \mathrm{TS}-1$ (impregnation). After $5 \mathrm{~h}$, the selectivity to propene oxide of $\mathrm{Au} / \mathrm{TS}-1$ (sol immobilization) is lower than that of the reduced $\mathrm{Au} / \mathrm{TS}-1$ (impregnation) by $14 \%$ (Fig. 12(b)).

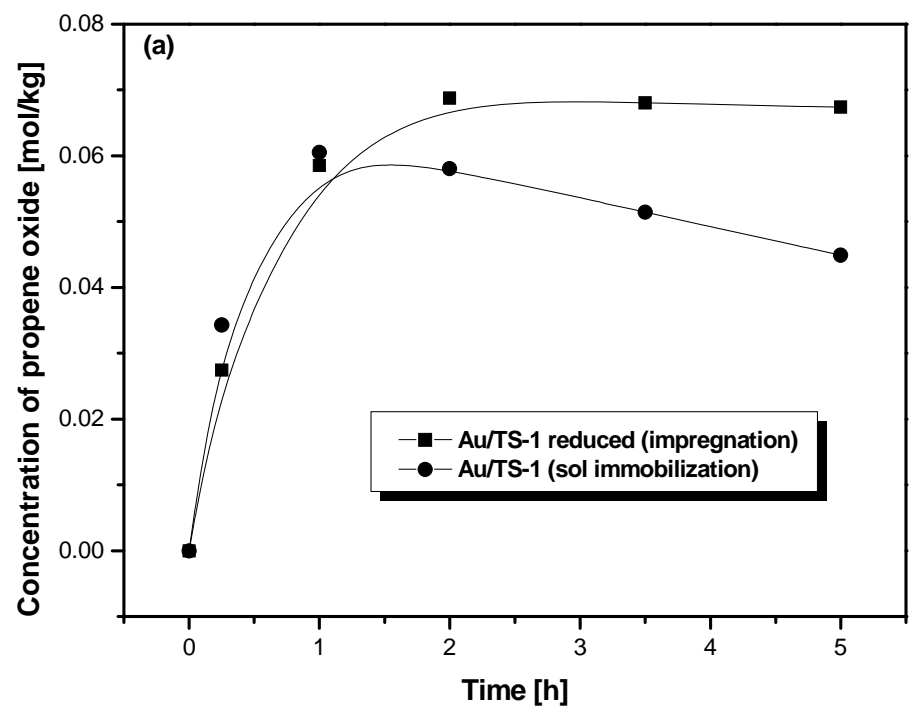




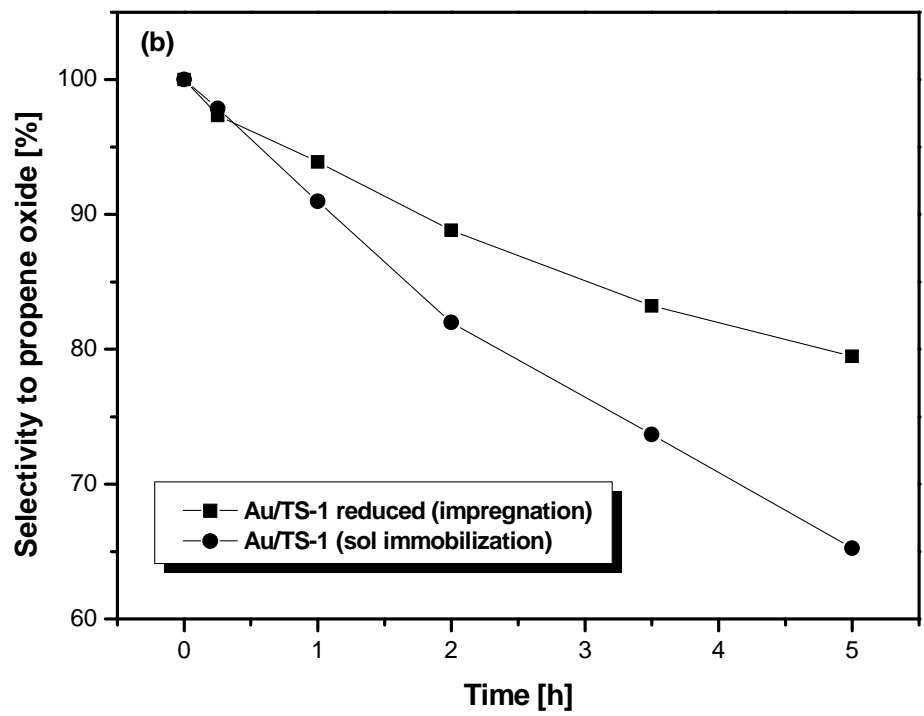

Fig. 12. Propene epoxidation over Au/TS-1 prepared by impregnation (reduction) and sol immobilization at normal operating conditions: (a) propene oxide production and (b) selectivity to propene oxide.

There is also a significant difference of hydrogen peroxide decomposition between two catalysts as shown in Fig. 13. The homogeneous dispersion of gold nanoparticles made the decomposition more vigorous.

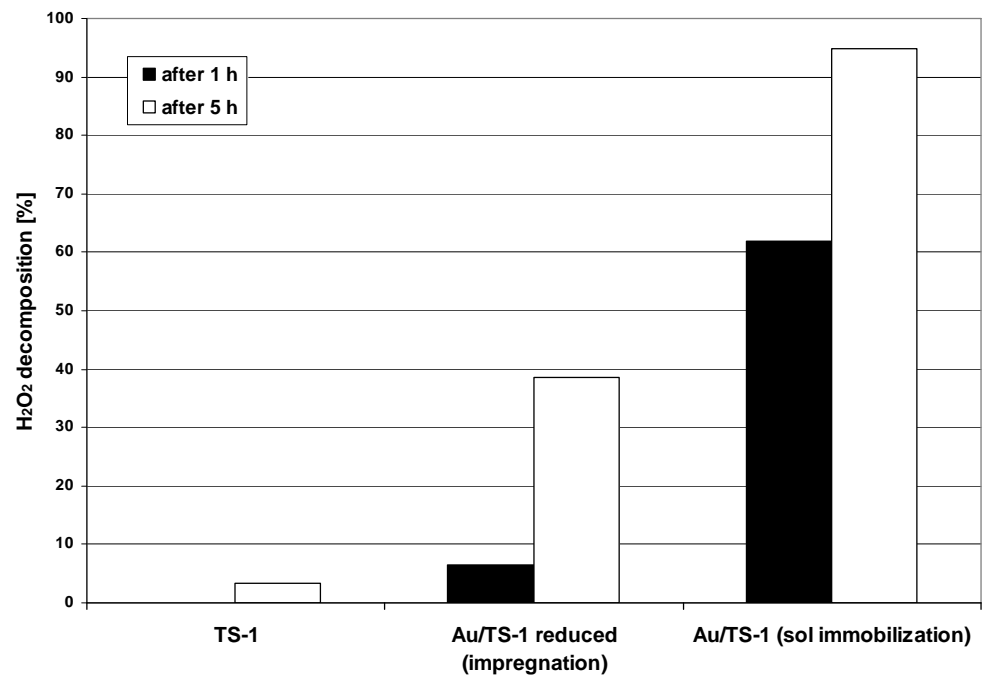

Fig. 13. Decomposition of hydrogen peroxide over $\mathrm{Au} / \mathrm{TS}-1$ prepared by sol immobilization. Conditions: $40{ }^{\circ} \mathrm{C}, 7$ bar $\mathrm{N}_{2}, 0.35 \mathrm{wt} \% \mathrm{H}_{2} \mathrm{O}_{2}, 50 \mathrm{wt} \% \mathrm{CH}_{3} \mathrm{OH}, 0.28 \mathrm{~g}$ of catalyst, $1000 \mathrm{rpm}$ stirring.

The increase of efficient surface area due to homogeneous dispersion of precious metal has a negative effect on the decomposition of hydrogen peroxide but can lead to a positive effect on the generation of 
hydrogen peroxide and propene oxide in the $\mathrm{H}_{2}-\mathrm{O}_{2}$ system because it is known that hydrogen peroxide is produced on the active sites of precious metal and reacts directly with propene before its decomposition [28]. Also, the higher initial rate of $\mathrm{Au} / \mathrm{TS}-1$ by sol immobilization shown in Fig. 12(a) presents the possibility of a positive effect on the production of propene oxide. Therefore, the sol immobilization method is recommended for the synthesis of precious metal containing TS-1 catalysts. However, the synthesis of precious metal containing TS-1 catalysts and reaction conditions need to be optimized to minimize the decrease of the selectivity to propene oxide in terms of reactor type employed.

\section{Conclusions}

The analysis results of catalysts showed no distinction between precious metal containing TS-1 catalysts and TS-1 alone except for the presence of gold and palladium peaks in the XRD spectra. This confirms that the MFI structure of TS-1 was not modified by the impregnation of precious metals.

The impregnation of precious metals had a profound effect on the hydrogen peroxide decomposition and the propene oxide production. In principle, the presence of precious metals vigorously catalyzed the side reactions and the hydrogen peroxide decomposition. The decomposition of hydrogen peroxide was more significant on palladium than on gold and the effect of treatment process on the decomposition was varied according to the kind of precious metal. Some of the precious metal containing TS-1 catalysts showed higher initial rates and propene oxide yields after $1 \mathrm{~h}$ than TS-1 alone but could not lead to higher propene oxide yields after $5 \mathrm{~h}$ because of the enhancement of side reactions. Finally, there was no catalyst with a higher propene oxide yield after the whole reaction time better than TS-1 alone.

The alloy of gold and palladium existing in the calcined Au-Pd/TS-1 decreased the hydrogen peroxide decomposition when compared with the dried $\mathrm{Au}-\mathrm{Pd} / \mathrm{TS}-1$ or the reduced $\mathrm{Au}-\mathrm{Pd} / \mathrm{TS}-1$, but failed to gain a high propene oxide yield because of the low reaction rate and the selectivity to propene oxide.

The exceptional performances of the dried catalysts could be explained satisfactorily by the leaching of precious metals into the reaction medium. Different from immobilized gold in the reduced or calcined catalysts, the leached gold nanoparticles remarkably catalyzed non-selective oxidation to generate byproducts.

The sol immobilization was found to be a more efficient method than simple impregnation for homogeneous dispersion of precious metal nanoparticles on TS-1 which would be favorable in the $\mathrm{H}_{2}-\mathrm{O}_{2}$ system, but the production rate of propene oxide and the selectivity to propene oxide seriously 
deteriorated with time, although the initial production rate of propene oxide was higher over $\mathrm{Au} / \mathrm{TS}-1$ prepared by sol immobilization. However, to clearly understand the influence of the degree of precious metal dispersion on the hydrogen peroxide decomposition and the production of propene oxide and byproducts, further work is required with various precious metal containing TS-1 catalysts prepared by sol immobilization in the $\mathrm{H}_{2} \mathrm{O}_{2}$ system. Also, more research needs to be undertaken to investigate simultaneously the formation of hydrogen peroxide and the production of propene oxide using a $\mathrm{H}_{2}-\mathrm{O}_{2}$ gas mixture in a batch and unstructured or structured reactors under continuous flow conditions.

\section{Acknowledgement}

Financial support by EPSRC (UK) is gratefully acknowledged.

\section{References}

[1] T.A. Nijhuis, M. Makkee, J.A. Moulijn, B.M. Weckhuysen, Ind. Eng. Chem. Res. 45 (2006) 34473459.

[2] W.G. Cheng, X.S. Wang, G. Li, X.W. Guo, S.J. Zhang, J. Catal. 255 (2008) 343-346.

[3] S.J. Khatib, S.T. Oyama, Catal. Rev. 57(3) (2015) 306-344.

[4] L.Y. Chen, G.K. Chuah, S. Jaenicke, J. Mol. Catal. A: Chem. 132 (1998) 281-292.

[5] W. Laufer, R. Meiers, W. Holderich, J. Mol. Catal. A: Chem. 141 (1999) 215-221.

[6] E.J. Beckman, Green Chem. 5 (2003) 332-336.

[7] X.W. Liu, X.S. Wang, X.W. Guo, G. Li, H.S. Yan, Catal. Lett. 97 (2004) 223-229.

[8] Q.F. Wang, L. Wang, J.X. Chen, W. Wu, Z.T. Mi, J. Mol. Catal. A: Chem. 273 (2007) 73-80.

[9] J.L. Zhao, J.C. Zhou, J. Su, H.C. Guo, X.S. Wang, W.M. Gong, AlChE J. 53 (2007) 3204-3209.

[10] S. Park, K.M. Cho, M.H. Youn, J.G. Seo, S.H. Baeck, T.J. Kim, Y.M. Chung, S.H. Oh, I.K. Song, Catal. Lett. 122 (2008) 349-353.

[11] S. Park, K.M. Cho, M.H. Youn, J.G. Seo, J.C. Jung, S.H. Baeck, T.J. Kim, Y.M. Chung, S.H. Oh, I.K. Song, Catal. Commun. 9 (2008) 2485-2488.

[12] G. Blanco-Brieva, M.P. de Frutos-Escrig, H. Martín, J.M. Campos-Martina, J.L.G. Fierro, Catal. Today 187(1) (2012) 168-172.

[13] V. Russo, R. Tesser, E. Santacesaria, M. Di Serio, Ind. Eng. Chem. Res. 52 (2013) 1168-1178. 
[14] B. Puértolas, A.K. Hill b, T. Garcíaa, B. Solsonac, L. Torrente-Murciano, Catal. Today (2015) 115127.

[15] M. Ghanta, D. R. Fahey, D. H. Busch, B. Subramaniam. ACS Sustainable Chem. Eng. 1 (2013) 268277.

[16] M.G. Clerici, G. Bellussi, U. Romano, J. Catal. 129 (1991) 159-167.

[17] G.F. Thiele, E. Roland, J. Mol. Catal. A: Chem. 117 (1997) 351-356.

[18] Y. Zuo, M. Wang, W. Song, X. Wang, X. Guo, Ind. Eng. Chem. Res. 51(32) (2012) 10586-10594.

[19] G. Wu, Y. Wang, , L. Wang, W. Feng, H. Shi, Y. Lin, T. Zhang, X. Jin, S. Wang, X. Wu, P.Yao , Chem. Eng. J. 215-216 (2013) 306-314.

[20] Y. Zuo, M. Liu T. Zhang, L. Hong, X. Guo, C. Song, Y. Chen, P. Zhu, C. Jayec, D. Fischer, RSC Adv. 5 (2015) 17897-17904.

[21] G. Li, J.W. Meng, X.S. Wang, X.W. Guo, React. Kinet. Catal. Lett. 82 (2004) 73-80.

[22] Y. Zuo, M. Liu, T. Zhang, C. Meng, X. Guo, C Song, ChemCatChem 7(17) (2015) 2660-2668.

[23] C. Hammond, G. Tarantino, Catalysis 5(4) (2015) 2309-2323.

[24] P.L. Short, Chem. Eng. News 87 (2009) 21.

[25] Q.L. Chen, E.J. Beckman, Green Chemistry 10 (2008) 934-938.

[26] A. Seubsai, M. Kahn, B. Zohour, D. Noon, M. Charoenpanich, S. Senkan, Ind. Eng. Chem. Res. 54(10) (2015) 2638-2645.

[27] R. Meiers, U. Dingerdissen, W.F. Holderich, J. Catal. 176 (1998) 376-386.

[28] R. Meiers, W.F. Holderich, Catal. Lett. 59 (1999) 161-163.

[29] R.A. Grey, P. Rangasamy, U.S. 6,194,591 (2001)

[30] G. Jenzer, T. Mallat, M. Maciejewski, F. Eigenmann, A. Baiker, Appl. Catal. A: Gen. 208 (2001) 125-133.

[31] T. Danciu, E.J. Beckman, D. Hancu, R. Cochran, R. Grey, D. Hajnik, J. Jewson, Angew. Chem. Int. Ed. 42 (2003) 1140-1142.

[32] W.F. Hoelderich, F. Kollmer, Pure Appl. Chem. 72 (2000) 1273-1288.

[33] W. Laufer, W.F. Hoelderich, Appl. Catal. A: Gen. 213 (2001) 163-171.

[34] W.F. Hoelderich, Appl. Catal. A: Gen. 194 (2000) 487-496.

[35] H. Peng, L. Xu, L. Zhang, K. Zhang, Y. Liu, H. Wu, P. Wu, J. Mat. Chem. 22 (2012) 14219.

[36] A. Prieto, M. Palomino, U. Díaz, and, A. Corma, Catal. Today 227 (2014) 87. 
[37] P. Landon, P.J. Collier, A.F. Carley, D. Chadwick, A.J. Papworth, A. Burrows, C.J. Kiely, G.J. Hutchings, Phys. Chem. Chem. Phys. 5 (2003) 1917-1923.

[38] Q.L. Chen, E.J. Beckman, Green Chem. 9 (2007) 802-808.

[39] G. Li, J. Edwards, A.F. Carley, G.J. Hutchings, Catal. Today 122 (2007) 361-364.

[40] J.K. Edwards, G.J. Hutchings, Angew. Chem. Int. Ed. 47 (2008) 9192-9198.

[41] J.K. Edwards, E. Ntainjua, A.F. Carley, A.A. Herzing, C.J. Kiely, G.J. Hutchings, Angew. Chem. Int. Ed. 48 (2009) 8512-8515.

[42] W.S. Lee, M.C. Akatay, E.A. Stach, F.H. Ribeiro, W.N. Delgass, J. Catal. 287 (2012) 178-189.

[43] W.S. Lee, L.C. Lai, M.C. Akatay, E.A. Stach, F.H. Ribeiro, W.N. Delgass, J. Catal. 296 (2012) 3142.

[44] C. Mennemann, P. Claus, Catal. Lett. 134 (2010) 31-36.

[45] G.W. Zhan, M.M. Du, J.L. Huang, Q.B. Li, Catal. Comm. 12 (2011) 830-833.

[46] G.W. Zhan, M.M. Du, D.H. Sun, J.L. Huang, X. Yang, Y. Ma, A.R. Ibrahim, Q.B. Li, Ind. Eng. Chem. Res. 50 (2011) 9019-9026.

[47] L. Xu, Y. Ren, H. Wu, Y. Liu, Z. Wang, Y. Zhang, J. Xu, H. Peng, P. Wu, J. Mat. Chem. 21 (2011) 10852-10858

[48] M. Taramasso, G. Perego, B. Notari, U.S. 4,410,501 (1983)

[49] J.D. Grunwaldt, C. Kiener, C. Woegerbauer, A. Baiker, J. Catal. 181 (1999) 223-233.

[50] A.J.H.P. van der Pol, J.H.C. van Hooff, Appl. Catal. A: Gen. 92 (1992) 93-111.

[51] A.J.H.P. van der Pol, A.J. Verduyn, J.H.C. van Hooff, Appl. Catal. A: Gen. 92 (1992) 113-130.

[52] S.B. Shin, D. Chadwick, Ind. Eng. Chem. Res. 49 (2010) 8125-8134.

[53] A. Thangaraj, R. Kumar, S.P. Mirajkar, P. Ratnasamy, J. Catal. 130 (1991) 1-8.

[54] G.D. Lee, S.K. Jung, Y.J. Jeong, J.H. Park, C.S. Suh, B.H. Ahn, S.S. Hong, J. Ind. Eng. Chem. 8 (2002) 22-27.

[55] G.D. Lee, S.K. Jung, Y.J. Jeong, J.H. Park, K.T. Lim, B.H. Ahn, S.S. Hong, Appl. Catal. A: Gen. 239 (2003) 197-208.

[56] L. Torrente-Murciano, Q. He, G. J. Hutchings, C. J. Kiely, D. Chadwick, ChemCatChem 6 (2014) 2531-2534.

[57] L. Torrente-Murciano, T. Villager, D. Chadwick, ChemCatChem 7 (2015) 925-927.

[58] X.S. Wang, X.W. Guo, G. Li, Catal. Today 74 (2002) 65-75. 
[59] X.H. Liang, Z.T. Mi, Y.L. Wu, L. Wang, E.H. Xing, React. Kinet. Catal. Lett. 80 (2003) 207-215.

[60] G. Li, J. EdwardS, A.F. Carley, G.J. Hutchings, Catal. Today 114 (2006) 369-371.

[61] Q.F. Wang, L. Wang, Z.T. Mi, Catal. Lett. 103 (2005) 161-164. 